\title{
FAMILY DECISION-MAKING ABOUT ORGAN DONATION: A SYSTEMATIC REVIEW
}

\author{
Makmor T, Abdillah N, NurulHuda MS, Raja Noriza RA, Roza Hazli Z \\ Faculty of Economics and Administration, University of Malaya, Kuala Lumpur
}

\section{Correspondence: \\ Makmor Tumin}

Department of Administrative Studies and Politics, Faculty of Economics and Administration, University of Malaya, 50603

Kuala Lumpur, Malaysia.

Email: makmor@um.edu.my

Phone no.: +603-79673690

\begin{abstract}
The family is an important factor that influences an individual's decision for organ donation. The number of studies addressing the family's role in organ donation is limited. It is imperative to explore these studies and offer recommendations that may help in addressing organ shortage. 15 studies with more than 2100 participants were selected for a systematic review. The studies were accessed by searching three databases: MEDLINE, Elsevier, and PsycINFO. This systematic review indicates that knowledge about brain death and the circumstances surrounding organ donation and transplantation are the most important factors that affect a family's decision regarding organ donation. Educational efforts targeting the family should be initiated, which can then guide the family's decision on organ donation. We suggest that educational efforts be consistent with other factors such as religious beliefs that influence the family's decision.
\end{abstract}

Keywords: deceased donation, family decision, family education, living donation, organ donation

\section{Introduction}

Many factors are considered when an individual is making a decision on organ donation. A systematic review of 18 studies involving 1,019 participants revealed that there are eight main factors that influence an individual's decision regarding organ donation. They are relational ties, religious beliefs, cultural influences, family influences, body integrity, interaction with the health-care system, knowledge about organ donation, and reservations about the process of organ donation (1).

Of these eight factors, the family is the most important. It is universally accepted that the family is responsible for shaping an individual's ethical considerations. Consequently, it can have a bearing on a person's willingness to donate organs. There have been only a very limited number of studies focusing on the family as the fundamental decision-making institution on organ donation. This paper aims to examine how the family institution plays a role in influencing the decision to donate organs.

There are three main reasons why we should focus on providing the family with information on organ donation if we are to improve organ donation. Firstly, the family can influence an individual to become a related living organ donor. Families are genetically and emotionally related to the patient, and they are often referred as potential donors before an appeal for organ donation is made to the public. Secondly, the family can provide the ethical basis and influence on an individual's decision to donate organs. The family, for instance, can influence the individual to sign up for organ donation. Thirdly, the family plays a major role in deciding on deceased organ donation. In this context, the family is the final decision maker and have the legal right to overrule the consent of the deceased for organ donation made whist still living. This is the legal procedure in most of the countries with organ donation systems (2). In Malaysia, for instance, the Human Tissue Act 1974 stipulates that the family's consent has to be taken before procuring organ(s) from the body of their loved ones, even when the deceased had registered to donate his organs before his death.

Taking into account the above arguments, it is thus imperative that we analyze the literature on the influence of the family in organ donation. Three things are of interest to us. We would like to identify from the literature the various factors that determine families' decision about encouraging living related organ donation. We would also like to examine the significance of the role various family members play in allowing relatives to pledge for organ donation. Finally, we would like to locate in the literature 
the factors that could contribute to a family's willingness to give consent to donate their relative's deceased organs. By focusing on these three issues, we hope that this systematic review will shed further light on the direct and indirect impact of the family on organ donation. The direct impact comes from the family role in allowing organs to be harvested from the deceased family member, while the indirect impact stems from the family's influence on the individual's decision to become an organ donor.

\section{Methods}

We reviewed and summarized 15 journal articles. We focused on three themes that were of concern to us. The first involved factors that influence a family's decision to encourage living related organ donation. There were seven studies, with more than 4,000 participants. The second concern involved factors that influenced families' decision to allow relatives to become organ donors. We identified two papers, with views from 155 respondents. The third concern involved factors that influenced families' consenting to deceased organ donation. We chose three articles with views from 550 respondents.

The articles were selected from three online databases, namely, MEDLINE, Elsevier, and PsycINFO. We used keywords such as "organ," "deceased donation," "living related," and "family influence" in order to retrieve relevant studies for each of the themes.

\section{Results}

As mentioned in the Methods section, we divided the literature into three groups based on factors influencing a family's decision about organ donation: becoming living donors, allowing a relative's pledge for organ donation, and allowing a deceased relative's organ donation.

\section{(i) Becoming living donors}

Previous studies looking at the family's role in influencing the decision to become a living donor can be grouped into emotional and nonemotional factors. In a literature review, Conrad and Murray (3) found that kidney recipient's emotional outlook is critical in determining the family's ability to influence living related organ donation. They concluded that kidney recipient's negative feelings and expressions played an important role in the family's ability to encourage living related organ donation.

Stothers et al.'s (4) study on 27 previous living donors and 387 relatives of patients listed on waiting lists for organs discovered that the ability of families to encourage living related organ donation could be due to pressure from constant requests. Pressures are often felt by wouldbe organ donors when family members or medical professionals made direct requests for living donation to the potential donor. Approximately $4 \%$ of living donors cited family pressure as the reason for them making an organ donation (4). Jacobs et al.'s (5) analysis of 524 previous living donors' responses revealed that the donors were more likely to feel pressured to donate if the recipient were a sibling or an offspring.

Rodrigue and Guenther's (5) review of the psychology of live liver donors found emotional concerns as the main factor influencing family members to agree on living organ donation, where the emotional links with the recipient often encouraged families to save or improve the quality of their loved one's life. Potential donors were also inspired to become living related organ donors because of feelings of responsibility, duty, or internal pressure to do the morally correct thing for their family members.

Some studies found that nonemotional rather than emotional factors influenced the decision on living organ donation. Lee et al. (7) concluded that knowledge of organ donation and transplantation determined the likelihood of family member to become a living donor. Their research collected responses from 209 individuals and found that the lack of knowledge about organ donation was one of the most important factors that discouraged one from being a living related donor. About $42 \%$ of the respondents, who had hesitated to donate (92 of 209 respondents) cited that the lack of information was a source of anxiety for them when deciding to donate their organs. The other reasons revealed by respondents that were indirectly related to the lack of knowledge of organ donation were the fear of pain and complications, death after surgery, and the inability to maintain a normal life after donation.

Another study cited the age of the family members as a determining factor in an individual's willingness to be living organ donor. Yang et al. (8) looked at the case of living organ donation in China for 302 family members of kidney failure patients. They found that the attitudes toward living related kidney donation were highly influenced by nonemotional factors, for instance the age of the family members. The study found that the respondents who were 45 years old and above were more in favor of organ donation than those aged 35 years and below. Besides the age of the potential donor, Yang et al. also confirmed Lee et al.'s results on the importance of knowledge of organ donation as a determinant of the willingness regarding living donation.

\section{(ii) Allowing a relative's pledge for organ donation}

Getting the family to understand organ donation is an important avenue to encourage organ donation from related members of the family. Various studies have reported that some individuals abstained from being organ donors merely because they failed to obtain permission from family members. A study on the attitudes of 141 Muslim Indo-Asians in West London toward transplantation in the United Kingdom found that most of the participants did not allow their children to obtain a donor card (9). One of the female respondents in the study stated that she had no objection in donating her organs, unlike her father who objected to her decision on donating organs. Another female respondent stated that she could not decide on the donation because it required permission from her husband. A study by Morgan et al. on 14 men and women 
of Caribbean descent, living in South London, reported that the fear brought about by the family members about body integrity and the thought of the body being "cut up" were some of the reasons why individuals chose not to support their relatives becoming donors (10).

\section{(iii) Allowing deceased relative's organ donation}

Three studies suggested that there were modifiable factors, which, if properly handled, could lead to families giving consent for deceased organ donation. The review of Simpkin et al. of 20 selected studies pertaining to alterable factors that influenced a family's decision on organ donation suggested three main factors. The first factor was inadequate knowledge of organ donation and brain death; the second was the process of requesting consent, the "who, when, and where" to request the consent; and finally, the effect on the prospective donor's health (11). In this context, Orøy et al.'s interviews with 16 nurses, 12 physicians, and 4 hospital chaplains concluded that the main problem faced in delivering the message of organ procurement from a deceased donor was choosing the most appropriate time to raise the issue to the deceased's family (12).

Ghorbani et al. (13) reported on the causes of family's refusal for organ donation and found that the poor acceptance of brain death was the major reason for a family to refuse organ donation. The study, which was conducted on 81 families of potential organ donors who had refused organ donation, found that $44.4 \%$ of the families indicated that uncertainty of the brain death circumstances was one of the reasons for not allowing deceased organ donation by their family members. Other factors such as unknown donor wishes and religious issues were also stated as leading reasons toward family's objection to deceased organ donation.

Organ trading has become a global concern in the last few decades, and many regulations have been introduced to fight this unethical practice in many countries. Families feared that their loved ones' organs-if they consent to donate-would not be used legally and ethically and have refused organ donation. Ghorbani et al. found that 9.9\% of families refused to donate their love ones' organs due to fear of organ sale (13).

Siminoff et al.'s study on 49 family members pointed out that there were other reasons for a family's disapproval of deceased organ donation. These reasons included families' lack of knowledge of the deceased's organ donation wishes, family members' lack of knowledge about the extent of the patient's brain injury, and the inability of medical professionals to clearly communicate to the family members on the extent of the patient's brain injury (14). Another study on 420 cases of deceased organ donation decision-making also revealed that communication among family members on organ donation was an important criterion, which influenced family members' decision to allow for deceased organ donation. The study found that families that conducted frequent conversations on organ donation were more likely to donate (15).

\section{Discussion}

This paper sets out to look at the influence of the family in determining organ donation. The family factor of organ donation is discussed from three aspects: encouraging related living donation, allowing a family member to pledge to donate organs after death, and consenting to deceased organ donation. In a collective point of view of the three aspects, we found from the literature that there are various factors that can influence a family's decision on organ donation. The factors can be categorized based on their importance as noted in the literature. In this context, knowledge about organ donation and transplantation and the pertinent circumstances surrounding them have been most cited among the studies reviewed in this paper, to affect all three themes discussed in this paper. This highlights the vital role of family education on organ donation and transplantation in influencing the rate of deceased and living organ donations.

Emotional factors, including the feelings of sympathy toward a family member who is in need of an organ, also play a crucial role in determining the willingness of an individual to become a living donor, especially among relatives. There are many other factors cited in the literature influencing the family's decision regarding organ donation, such as the procedure/process of getting consent from the family members in the case of deceased donation, the fear of organ trading, religion-related matters, and others. The analysis of the literature puts family education central in any initiative to increase organ donation rates. Future studies should be focused on methods of delivering information to families, to enable them to resolve their organ donation issues (see Table 1).

Table 1: Factors influencing family decision on living and deceased organ donation.

\begin{tabular}{|c|c|}
\hline Factor & Study \\
\hline $\begin{array}{l}\text { Knowledge about brain death and } \\
\text { organ donation and transplantation. }\end{array}$ & (7), (11), (13), and (14) \\
\hline Emotional factors & $(2),(3),(4),(5)$, and $(6)$ \\
\hline \multicolumn{2}{|l|}{ Others } \\
\hline $\begin{array}{l}\text { The request process of organ } \\
\text { procurement }\end{array}$ & (12) and (13) \\
\hline Body integrity & $(1),(10)$, and (13) \\
\hline Fear of organ trading & (11) \\
\hline Religious matters & (11) \\
\hline $\begin{array}{l}\text { Communication among family } \\
\text { members }\end{array}$ & (15) \\
\hline Donor's age & (8) \\
\hline
\end{tabular}


This paper provides a precise summary of recent literature findings on family's decision making on organ donation. The studies included in this article were randomly selected from the limited number of available studies pertaining to the scope of this research. A wider systematic search of the literature may provide a more comprehensive review on this topic. We believe however that our review provides important guidelines for future research in this area.

\section{Conclusion}

We conclude that the improvement of organ donation rates through the family channel requires adequate and appropriate efforts to educate people about organ donation and transplantation, especially on brain death and the circumstances surrounding the issue. The lack of knowledge is the factor which may impede organ donation, whether living or deceased. In the case of living donation, more often than not, emotional factors influence not only an individual to become an organ donor but also a family's decision to put pressure on the prospective donor. However, the review suggests that emotional factors must be complemented by knowledge of living donation.

In the case of deceased organ donation, it is most important to educate the family members about the definition and condition of brain death, besides disseminating information regarding organ donation, such as body integrity, religious acceptance toward organ donation, as well as the process of organ procurement. Choosing the right time to request the family's consent to donate their loved ones' organs is crucial in this context.

Given our understanding of the importance of knowledge in influencing a family's decision and acceptance toward organ donation, it is of fundamental concern to tackle the issue of dispersing information to the family members. We suggest that future studies focus on answering the question of "what are the appropriate educational methods to enhance family knowledge about organ donation and transplantation?"

\section{Acknowledgments}

The authors would like to thank Mr. Khaled Tafran who helped in preparing this manuscript and The Ministry of Education, Malaysia, and University of Malaya for funding the research under the Exploratory Research Grant Scheme and the University of Malaya Research Grant Scheme. This study has been granted with Exploratory Research Grant Scheme 2012 (Project No: ER019-2012A) and University of Malaya Research Grant Scheme 2013 (RG490-13HTM).

\section{References}

1. Irving $\mathrm{M}$, Tong $\mathrm{A}$, Jan S et al. Factors that influence the decision to be an organ donor: a systematic review of the qualitative literature. Nephrol Dial Transpl. 2011; 27(6):2526-33.
2. Conrad NE, Murray LR. The psychosocial meanings of living related kidney organ donation: recipient and donor perspectives: literature review. Nephrology Nursing Journal. 1999; 26(5):485-90.

3. Stothers L, Gourlay WA, Liu L. Attitudes and predictive factors for live kidney donation: A comparison of live kidney donors versus nondonors. Kidney Int. 2005; 67:1105-11.

4. Jacobs C, Johnson E, Anderson K, Gillingham K, Matas A. Kidney transplants from living donors: How donation affects family dynamics. Adv. Renal Replace. Ther. 1998; 5:89-97.

5. Rodrigue JR, Guenther RT. Psychosocial evaluation of live donors. Curr Opin Organ Tran 2007; 11:234-40.

6. Hilhorst MT, Kranenburg LW, Busschbach JJV. Should health care professionals encourage living kidney donation? Med Health Care Philos 2007; 10:81-90.

7. Lee $\mathrm{SH}$, Jeong JS, Ha HS et al. Decision-related factors and attitudes toward donation in living related liver transplantation: ten-year experience. Transplant $P$ 2005; 37:1081-84.

8. Yang $H$, Wang $Z$, Li H, Zeng F. Factors influencing attitudes of relatives of renal failure patients toward living kidney donation: central China. Transplant $P$ 2012; 144:2921-24.

9. AlKhawari, FS, Stimson GV, Warrens AN. Attitudes toward transplantation in U.K. Muslim Indo-Asians in west London. Am J Transplant. 2005; 15(6):1326-31.

10. Morgan M, Mayblin M, Jones R. Ethnicity and registration as a kidney donor: the significance of identity and belonging. Soc Sci Med 2008; 66:147-58.

11. Simpkin AL, Robertson LC, Barber VS, Young JD. Modifiable factors influencing relatives' decision to offer organ donation: Systematic review. Brit Med J 2009; 339:b991.

12. Orøy A, Strømskag K E, Gjengedal E. Approaching families on the subject of organ donation: A phenomenological study of the experience of healthcare professionals. Intensive Crit Care Nurs 2013; 29(4):202-11.

13. Ghorbani HR, Khoddami-Vishteh O, Ghobadi S, Shafaghi A, Rostami Louyeh K, Najafizadeh. Causes of family refusal for organ donation. Transplant $P$. 2011; 43(2):405-6.

14. Sque M, Long T, Payne S. Organ donation: key factors influencing families' decision-making. Transplant $P$. 2005; 37(2):543-46.

15. Siminoff LA, Gordon N, Hewlett J, Arnold RM. Factors influencing families' consent for donation of solid organs for transplantation. Jama. 2001; 286 (1):7177. 